Evans J, Mackison D, Swanson V, Donnan PT, Emslie-Smith AM \& Lawton J (2013) Self-monitoring of blood glucsoe in type 2 diabetes: Patients' perceptions of 'high' readings, Diabetes Research and Clinical Practice, 102 (1), pp. e5-e7.

This is the peer reviewed version of this article

NOTICE: this is the author's version of a work that was accepted for publication in Diabetes Research and Clinical Practice resulting from the publishing process, such as peer review, editing, corrections, structural formatting, and other quality control mechanisms may not be reflected in this document. Changes may have been made to this work since it was submitted for publication. A definitive version was subsequently published in Diabetes Research and Clinical Practice, [VOL 102, ISS 1 (2013)] DOI:

http://dx.doi.org/10.1016/j.diabres.2013.07.011 


\title{
Self-monitoring of blood glucose in type 2 diabetes: patients' perceptions of 'high' readings
}

\author{
Josie MM Evans $\mathrm{PhD}^{1}$, Senior Lecturer in Public Health \\ Dionne Mackison $\mathrm{PhD}^{1}$, Research Fellow \\ Vivien Swanson $\mathrm{PhD}^{2}$, Senior Lecturer \\ Peter T Donnan $\mathrm{PhD}^{3}$, Professor of Epidemiology and Biostatistics \\ Alistair Emslie-Smith $\mathrm{MD}^{4}$, General Practitioner \\ Julia Lawton $\mathrm{PhD}^{5}$, Professor of Health and Social Science
}

\footnotetext{
${ }^{1}$ School of Nursing, Midwifery and Health, University of Stirling, Scotland, UK

${ }^{1}$ School of Natural Sciences, University of Stirling, Scotland, UK

${ }^{3}$ Dundee Epidemiology and Biostatistics Unit, Division of Population Health Sciences, Medical Research Institute, University of Dundee, Scotland, UK

${ }^{4}$ The Mill Practice, Dundee, Scotland, UK

${ }^{5}$ Centre for Population Health Sciences, University of Edinburgh, Scotland, UK
}

\section{Correspondence to:}

Dr Josie MM Evans PhD

School of Nursing, Midwifery and Health

University of Stirling

Stirling

Scotland

UK

FK9 4LA

Tel: $01786-466352$

Fax: 01786-466333

E mail: josie.evans@stir.ac.uk

\section{No. of Figures: 1}

Word count: 465

Running title: Patients' perceptions of high blood glucose readings

Funding: This study was funded by the Chief Scientist Office, Scotland (reference $\mathrm{CZH} / 4 / 483)$. 
We recently published data on self-monitoring of blood glucose (SMBG) behaviour among non-insulin treated patients with type 2 diabetes mellitus in Tayside, Scotland, and their behavioural responses to SMBG readings ${ }^{1}$. We now present additional data relating to the perceptions of high readings of 207 patients (58\% male; mean age 63 years; range 36-76 years). They all had electronic records of SMBG prescriptions dispensed and were a representative sample recruited from primary care ${ }^{1}$. Diabetes duration ranged from $<2$ years $(8 \%)$ to $>10$ years $(29 \%)$. $80 \%$ were treated with metformin and/or sulphonylureas, $10 \%$ with injections of exenatide or liraglutide, and $12 \%$ by diet/lifestyle. Patients were asked to indicate what blood glucose readings that they 'were happy with', and those that they 'considered to be high'. For specified values, we calculated the proportion that would be 'happy with' these readings (Fig 1), with the majority being 'happy with' readings between 5 and $7 \mathrm{mmol} / \mathrm{l}$. Notably, though, 35\% were 'happy with' $8 \mathrm{mmol} / 1$, and $17 \%$ with $9 \mathrm{mmol} / \mathrm{l}$. Although these values were not related to specific times of the day, only $11(5 \%)$ patients reported that they checked their blood glucose levels after meals (when higher values are acceptable). When patients were asked what they considered to be a 'high' reading, some gave very specific ranges (e.g. '12.9 to 13'; '10.5-11.1') while others were more general (e.g. 'anything above 10'; 'double-digits'). Fig 1 shows the proportions of patients who considered specified values (or over) to be high. Where a range was given, we determined the lowest value of this range. For $68 \%$ of patients, this was $10 \mathrm{mmol} / \mathrm{l}$. For $10 \%$, it was $16 \mathrm{mmol} / \mathrm{l}$. Interestingly, 128 of the patients reported having received information/education on SMBG, 112 of whom stated that they had been told what their targets should be. 
Although these findings may help to explain the lack of empirical evidence surrounding the clinical benefits of monitoring (ie; the failure of many studies to identify an association between SMBG and improved glycaemic control may be because many patients are satisfied with high blood glucose readings and do not respond to readings recognized clinically to be high), they do need to be interpreted with caution. While many patients may not have knowledge of appropriate target ranges, it may also be that some use SMBG principally to avoid hypoglycaemia (around half of our patients were treated with sulphonylureas). Clinicians therefore need to understand the particular reasons and motivations of patients who self-monitor when they discuss target ranges, and also be aware that there may be upward slippage in patients' targets over time (as observed among patients with type 1 diabetes for a variety of reasons ${ }^{2}$ ). If patients do wish to continue SMBG, they need to have education on appropriate blood glucose level targets for their particular context, and this may need to be re-inforced over time.

1. Evans JMM, Mackison D, Swanson V, Donnan PT, Emslie-Smith A, Lawton J. Self-monitoring among non-insulin treated patients with type 2 diabetes mellitus: Patients' behavioural responses to readings and associations with glycaemic control. Diabetes Research and Clinical Practice 2013; 100: 235-242.

2. Rankin D, Cooke DD, Heller S, Elliott J, Amiel S, Lawton J. Experiences of using blood glucose targets when following an intensive insulin regimen: a qualitative longitudinal investigation involving patients with Type 1 diabetes. Diabetic Medicine 2012: DOI: 10.1111/j.1464-5491.2012.03670.x 
1. Fig 1: Proportions of patients who would be 'happy with' readings of a specified level (mmol/l) (upper panel), and proportions who considered readings of a specified level (mmol/l) to be 'high' (lower panel)
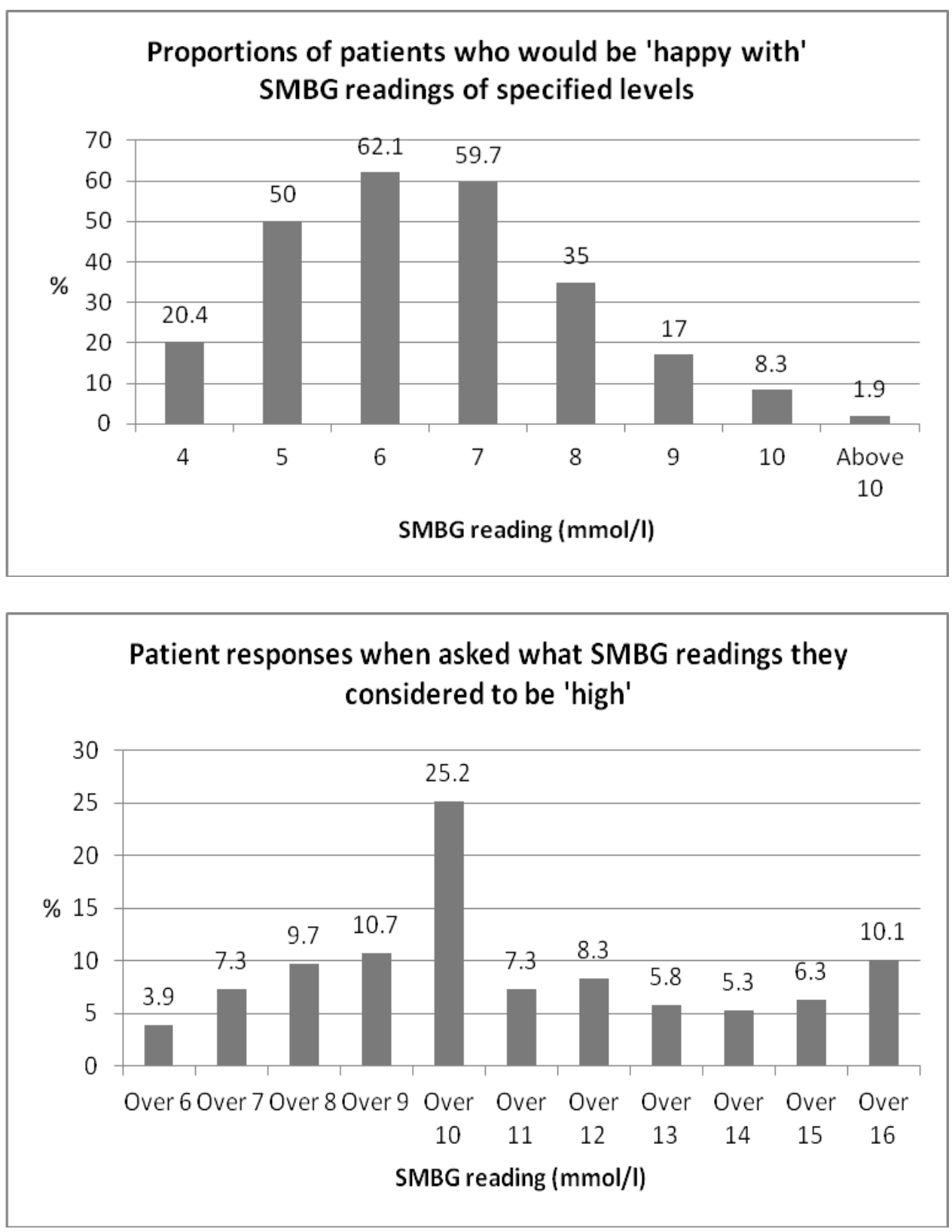
